\title{
BMJ Open Ozone air pollution and ischaemic stroke occurrence: a case-crossover study in Nice, France
}

\author{
Laurent Suissa, ${ }^{1}$ Mikael Fortier, ${ }^{2}$ Sylvain Lachaud, ${ }^{1}$ Pascal Staccini, ${ }^{3}$ \\ Marie-Hélène Mahagne ${ }^{1}$
}

To cite: Suissa L, Fortier M, Lachaud S, et al. Ozone air pollution and ischaemic stroke occurrence: a casecrossover study in Nice, France. BMJ Open 2013;3: e004060. doi:10.1136/ bmjopen-2013-004060

- Prepublication history and additional material for this paper is available online. To view these files please visit the journal online (http://dx.doi.org/10.1136/ bmjopen-2013-004060).

Received 18 September 2013 Revised 25 October 2013 Accepted 14 November 2013

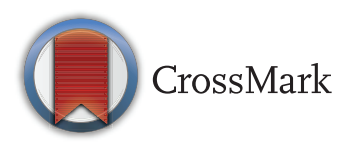

${ }^{1}$ Stroke Center, University Hospital of Nice, Nice, France ${ }^{2}$ Department of Emergency Medicine, University Hospital of Nice, Nice, France ${ }^{3}$ Department of Medical Information, University Hospital of Nice, Nice, France

Correspondence to Dr Laurent Suissa; suissa.laurent@free.fr

\section{ABSTRACT}

Objectives: Relationship between low-level air pollution and stroke is conflicting. This study was conducted to document the relationship between outdoor air pollution and ischaemic stroke occurrence. Design: Time-stratified case-crossover analysis. Setting: University Hospital of Nice, France.

Participants: All consecutive patients with ischaemic stroke living in Nice admitted in the University Hospital of Nice (France) between January 2007 and December 2011.

Main outcome measure: Association (adjusted OR) between daily levels of outdoor pollutants (ozone $\left(\mathrm{O}_{3}\right)$, nitrogen dioxide $\left(\mathrm{NO}_{2}\right)$, particulate matter (PM10) and sulfur dioxide $\left(\mathrm{SO}_{2}\right)$ ) and ischaemic stroke occurrence. Results: 1729 patients with ischaemic stroke (mean age: $76.1 \pm 14.0$ years; men: $46.7 \%$ ) were enrolled. No significant association was found between stroke occurrence and short-term effects of all pollutants tested. In stratified analysis, we observed significant associations only between recurrent $(n=280)$ and large artery ischaemic stroke $(n=578)$ onset and short-term effect of $\mathrm{O}_{3}$ exposure. For an increase of $10 \mu \mathrm{g} / \mathrm{m}^{3}$ of $\mathrm{O}_{3}$ level, recurrent stroke risk (mean D-1, D-2 and D-3 lag) was increased by $12.1 \%(95 \% \mathrm{Cl} 1.5 \%$ to $23.9 \%)$ and large artery stroke risk (mean D-3 and D-4 lag) was increased by $8 \%(95 \% \mathrm{Cl} 2.0 \%$ to $16.6 \%)$. Linear dose-response relationship for both subgroups was found.

Conclusions: Our results confirm the relationship between low-level $\mathrm{O}_{3}$ exposure and ischaemic stroke in high vascular risk subgroup with linear exposureresponse relation, independently of other pollutants and meteorological parameters. The physiopathological processes underlying this association between ischaemic stroke and $\mathrm{O}_{3}$ exposure remain to be investigated.

\section{INTRODUCTION}

Outdoor air pollution is considered as a major environmental health issue, responsible for an excess of death in the world. It is defined as any undesirable modification of air by substances either toxic or likely to have

\section{Strengths and limitations of this study}

- The relationship between low-level air pollution and stroke is conflicting. This article confirms the relationship between low-level ozone exposure and ischaemic stroke in high vascular risk subgroup with linear exposure-response relationship, independently of other pollutants and meteorological parameters. PM2.5 was not studied because it was not monitored in Nice.

adverse effects on health. Outdoor air pollutants are known to increase morbidity and mortality of respiratory diseases. ${ }^{1}$ However, in the 1950s and 1960s, epidemiological studies of acute severe pollution episodes have also shown an increasing cardiovascular and cerebrovascular mortality risk. ${ }^{2}$ A link between acute air pollution and stroke mortality has been reported for the first time in the London fog incident study in December $1952 .{ }^{2}$ In the last decades, the consequences of low-level air pollution on cardiovascular mortality and morbidity have been clearly described. ${ }^{3-6}$ By analogy, a few studies have examined the role of short-term air pollution on ischaemic stroke but actually no conclusion could be generalised. ${ }^{3}$ 5-24 The purpose of the present study was to document the relationship between the characteristics of outdoor air pollution and the occurrence of ischaemic stroke.

\section{MATERIALS AND METHODS \\ Population studied}

We performed a 5-year (2007-2011) casecrossover analysis in Nice, France. We retrospectively enrolled consecutive patients with stroke admitted at the University Hospital of Nice between January 2007 and December 2011. Querying French DRG-based database (PMSI: Programme de Médicalisation des Systèmes d'Information) with I60-I69 codes 
from the International Classification of Diseases (10th revision), we screened all patients hospitalised for stroke. We filtered the sample to patients living in Nice (geographical area defined by zip codes: 06000, 06100, 06200 and 06300). The diagnosis of ischaemic stroke was reviewed and confirmed by a panel of neurologists using clinical and radiological data of medical records. Patients with another diagnosis than stroke were excluded. Demographic data, vascular risk factors (WHO definitions), clinical and radiological characteristics of stroke were also collected from medical records.

\section{Outdoor air pollution and meteorological data}

Nice is an urban city situated in the south-eastern part of France on the Mediterranean coast. According to the latest census, Nice has a population of 340735 in 2009. Its climate is temperate and qualified as Mediterranean type. Surrounded by hills and mountains (south Alps), the city of Nice is sheltered from continuous violent winds. Outdoor air pollution comes mainly from traffic due to high density of roads and an international airport (first one in France after Paris airports).

Air pollution data were obtained from the regional agency for air quality monitoring (AirPACA). Exposure measurements during the study period were carried out in 2 of 13 permanent monitoring stations in the study area. Measures $\left(\mu \mathrm{g} / \mathrm{m}^{3}\right)$ were performed in an urban station (Cagnes Ladoumègue) for following atmospheric pollutants: particulate matter (PM10; tapered element oscillating microbalance), nitrogen dioxide $\left(\mathrm{NO}_{2}\right)$ (chemiluminescence), sulfur dioxide $\left(\mathrm{SO}_{2}\right.$; ultraviolet photometry) and ozone $\left(\mathrm{O}_{3}\right.$; ultraviolet photometry). Missing values were replaced by measures performed by the observational monitoring station located at Nice Airport. We computed for each pollutant during $24 \mathrm{~h}$ average and specifically for $\mathrm{O}_{3}$ during $8 \mathrm{~h}$ daytime periods.

Daily meteorological data were obtained from the National Meteorological Office of Nice, including temperature $\left({ }^{\circ} \mathrm{C}\right)$ and humidity $(\%)$. Moreover, data on influenza epidemics (weekly count) in the region of Provence-Alpes-Cote-d'Azur were obtained from the Sentiweb network.

\section{Statistical analysis}

Continuous variables were expressed as mean (SD) or median (IQR), and categorical variables as percentages. Spearman correlation coefficients ( $r$ ) between air pollutants and atmospheric parameters were calculated. The time-stratified case-crossover design was used to examine the relationship between short-term effects of outdoor air pollutants and stroke. In this design, each participant enrolled was his own control. Case days were defined as the day of stroke. Control days were defined as the same day of the same stratum as the case day. Study time was stratified by months. Therefore, explicative variable levels at the case day were compared with levels of the same variables at control days. This method has the main advantage to control individual factors, the day of the week, season and time trend. ${ }^{24}$ Conditional logistic regression was performed to estimate the association between short-term effects of each air pollutant measured and stroke onset. OR and 95\% CI for a $10 \mu \mathrm{g} / \mathrm{m}^{3}$ increase of pollutant level were adjusted for temperature and humidity with a 1-day lag, influenza epidemics and holidays without day lag. The pollutant exposure was tested in models for 1-day, 2-day or 3-day lag. Stratified analyses by subgroups were performed according to age, gender, risk vascular factors (tobacco use, diabetes mellitus, hypercholesterolaemia and hypertension) and stroke aetiological subtypes according to the Trial of ORG 10172 in acute stroke treatment (TOAST). We evaluated dose-response relationships across four exposure levels of pollutants studied, and the first quartile was used as the reference group. A p value less than 0.05 was considered as significant. The data were analysed using Stata V.10.0 SE software.

\section{RESULTS}

During the study period (January 2007 to December 2011), there were 2067 patients living in Nice and were admitted to the University Hospital Center for ischaemic stroke based on the DRG database. After neurologists review of medical records, 1729 patients with ischaemic stroke were enrolled for final analysis. Six hundred and twenty (35.9\%) of these patients were hospitalised in the stroke unit. According to the last population census of 2009, annual ischaemic stroke incidence rates (by $100000)$ in the studied area were, respectively, from 2007 to 2011: 100, 100, 98, 96 and 112. The mean age was $76.1 \pm 14.0$ years, and $46.7 \%$ were men (table 1 ).

The distribution of air pollutants and meteorological variables is shown in table 2. Spearman correlation coefficients ( $r$ ) were ranged from 0.01 to 0.25 between each studied pollutants, except between $\mathrm{O}_{3}$ and $\mathrm{NO}_{2}(\mathrm{r}=$ $-0.54)$. Correlation coefficient between minimal temperature and $\mathrm{O}_{3}$ was $\mathrm{r}=0.67$ (see online supplementary table I).

No significant association was found between stroke occurrence and short-term effects of all pollutants tested. In addition, we performed stratified subgroup analysis according to gender, age by decade, incident/ recurrent stroke status, vascular risk factors, presence of atrial fibrillation and stroke aetiological subgroups. We measured only significant associations between stroke and short-term effect of $\mathrm{O}_{3}$ in following both groups: recurrent $(n=280)$ and large artery stroke $(n=578)$ (table 3). In recurrent stroke subgroup, for an increase of $10 \mu \mathrm{g} / \mathrm{m}^{3}$ of $\mathrm{O}_{3}$ level (mean D-1, D-2 and D-3 lag), stroke risk was significantly increased by $12.1 \%(95 \%$ CI $1.5 \%$ to $23.9 \%$ ). Adjusted $\mathrm{OR}$ between $\mathrm{O}_{3}$ exposure (mean D-3 and D-4) and large artery stroke subgroup was 1.080 (95\% CI 1.002 to 1.166$)$. No significant association was observed with other pollutants than $\mathrm{O}_{3}$. Adjusted in two-pollutant models, OR was not affected. 
Table 1 Baseline characteristics of patients with ischaemic stroke (incident and recurrent) hospitalised in Nice University Hospital from 2007 to 2011

\begin{tabular}{|c|c|c|c|c|}
\hline & $\begin{array}{l}\text { All patients } \\
(n=1729)\end{array}$ & $\begin{array}{l}\text { Incident } \\
\mathrm{n}=1449(83.81 \%)\end{array}$ & $\begin{array}{l}\text { Recurrent } \\
n=280(16.19 \%)\end{array}$ & p Value \\
\hline \multicolumn{5}{|l|}{ Demographic data } \\
\hline Men & $808(46.73)$ & $683(47.14)$ & $125(44.64)$ & 0.0044 \\
\hline Age (years) & $76.06 \pm 14.04$ & $75.48 \pm 14.29$ & $79.01 \pm 12.33$ & $<0.0001$ \\
\hline$<55$ & $141(8.16)$ & $132(9.11)$ & $9(3.21)$ & 0.0011 \\
\hline $55-64$ & $186(10.76)$ & $155(10.70)$ & 31 (11.07) & 0.8532 \\
\hline $65-74$ & $324(18.74)$ & $279(19.25)$ & $45(16.07)$ & 0.2114 \\
\hline $75-84$ & $524(30.31)$ & $438(30.23)$ & $86(30.71)$ & 0.8712 \\
\hline$\geq 85$ & $554(32.04)$ & $445(30.71)$ & 109 (38.93) & 0.0071 \\
\hline \multicolumn{5}{|l|}{ Cardiovascular risk factors } \\
\hline Diabetes mellitus & $311(17.99)$ & $249(17.18)$ & $62(22.14)$ & 0.0481 \\
\hline Hypertension & 998 (57.72) & $803(55.42)$ & $195(69.64)$ & $<0.0001$ \\
\hline Dyslipidaemia & $441(25.51)$ & $348(24.02)$ & 93 (33.21) & 0.0012 \\
\hline Current smoker & $410(23.71)$ & $357(24.64)$ & 53 (18.93) & 0.0398 \\
\hline Overweight & $226(13.07)$ & $204(14.08)$ & $22(7.86)$ & 0.0047 \\
\hline Coronary artery disease & $263(15.21)$ & $209(14.42)$ & 54 (19.29) & 0.0381 \\
\hline Atrial fibrillation & $527(30.48)$ & $433(29.88)$ & 94 (33.57) & 0.2198 \\
\hline \multicolumn{5}{|c|}{ Classification of stroke aetiological subtypes (TOAST) } \\
\hline Large artery & $578(33.43)$ & $479(33.06)$ & 99 (35.36) & 0.4552 \\
\hline Cardioembolic & $563(32.56)$ & 469 (32.37) & 94 (33.57) & 0.6938 \\
\hline Lacunar stroke & $153(8.85)$ & $129(8.90)$ & $24(8.57)$ & 0.8582 \\
\hline Other determined aetiology & $43(2.49)$ & $40(2.76)$ & $3(1.07)$ & 0.0966 \\
\hline Undetermined aetiology & 392 (22.67) & $332(22.91)$ & $60(21.43)$ & 0.5872 \\
\hline Hospitalisation in stroke unit & $620(35.86)$ & $546(37.68)$ & $74(26.43)$ & 0.0003 \\
\hline
\end{tabular}

TOAST, Trial of ORG 10172 in acute stroke treatment.

Using $\mathrm{O}_{3}$ quartiles (1st quartile as the reference group), linear dose-response relationship for both subgroups was observed (figure 1). Baseline characteristics in recurrent stroke and large artery stroke subgroups are shown in figure 2.

\section{DISCUSSION}

Our study assessed the short-term effect of $\mathrm{O}_{3}$ exposure on a selected population of ischaemic stroke in a city especially polluted by $\mathrm{O}_{3}$. An elevation of $10 \mu \mathrm{g} / \mathrm{m}^{3}$ of $\mathrm{O}_{3}$ concentration increases stroke risk with few days lag in recurrent $(\approx 12 \%)$ and large artery stroke $(\approx 8 \%)$ subgroups only. Linear dose-response relationship was observed systematically in both groups. In these groups, the common feature of the patients was that they cumulate vascular risk factors. No significant association was found between all ischaemic stroke groups and atmospheric pollutants studied $\left(\mathrm{O}_{3}, \mathrm{NO}_{2}, \mathrm{SO}_{2}\right.$ and PM10).

Several studies have investigated the association between outdoor air pollution and stroke. ${ }^{35-24}$ Results of these studies are conflicting and hamper generalisation of conclusions. Heterogeneous methodological considerations are the main explanation of this conflict. Methodological differences are observed in patient selection, study design, outcomes choice (incidence, hospital admission, mortality) and assessment of individual exposure to selected pollutants. ${ }^{20} \mathrm{Few}$ published studies investigated especially the association between occurrence of ischaemic stroke and $\mathrm{O}_{3}$ exposure using the case-

Table 2 Distribution of air pollution concentrations and meteorological parameters in Nice (France) between 2007 and 2012

\begin{tabular}{lrrrrrrr}
\hline & Mean & \multicolumn{1}{c}{ SD } & Minimum & Quartile 1 & Median & Quartile 3 & Maximum \\
\hline Ozone daily $8 \mathrm{~h}$ average $\left(\mu \mathrm{g} / \mathrm{m}^{3}\right)$ & 80.74 & 31.78 & 4.63 & 54.75 & 84.38 & 105.38 & 157.27 \\
Ozone daily $1 \mathrm{~h}$ maximum $\left(\mu \mathrm{g} / \mathrm{m}^{3}\right)$ & 92.37 & 31.32 & 7.00 & 69.00 & 94.00 & 115.00 & 197.00 \\
Ozone $24 \mathrm{~h}$ average $\left(\mu \mathrm{g} / \mathrm{m}^{3}\right)$ & 52.20 & 22.89 & 4.00 & 32.58 & 53.29 & 69.02 & 111.13 \\
$\mathrm{PM}_{0}\left(\mu \mathrm{g} / \mathrm{m}^{3}\right)$ & 28.48 & 9.81 & 1.00 & 22.00 & 28.00 & 34.00 & 74.00 \\
$\mathrm{NO}_{2}\left(\mu \mathrm{g} / \mathrm{m}^{3}\right)$ & 26.22 & 8.69 & 3.00 & 20.00 & 25.00 & 32.00 & 59.00 \\
$\mathrm{SO}_{2}\left(\mu \mathrm{g} / \mathrm{m}^{3}\right)$ & 1.23 & 1.18 & 0.00 & 0.00 & 1.00 & 2.00 & 10.00 \\
Minimum temperature $\left({ }^{\circ} \mathrm{C}\right)$ & 13.02 & 5.98 & -1.60 & 7.80 & 12.90 & 18.20 & 25.90 \\
Maximum humidity $(\%)$ & 81.40 & 9.07 & 40.00 & 76.00 & 83.00 & 88.00 & 97.00 \\
\hline
\end{tabular}

$\mathrm{NO}_{2}$, nitrogen dioxide; $\mathrm{PM} 10$, particulate matter; $\mathrm{SO}_{2}$, sulfur dioxide. 
Table 3 Adjusted ORs between ischaemic stroke and outdoor pollutants exposure for an increase of $10 \mu \mathrm{g} / \mathrm{m}^{3}$ in Nice (France) between 2007 and 2011 All ischaemic stroke $(n=1729)$ Recurrent stroke $(n=280)$ p Value aOR $\quad \begin{aligned} & 95 \% \mathrm{Cl} \\ & \mathrm{n}\end{aligned}$

p Value $95 \% \mathrm{Cl}$

Ozone

D-1 $\begin{array}{lllllll}8 \mathrm{~h} \text { average } & 0.9917 & 0.9584 & \text { to } & 1.0261 & 0.633 & 1.0899\end{array}$ $24 \mathrm{~h}$ average D-2 $\begin{array}{llllll}8 \mathrm{~h} \text { average } & 0.9976 & 0.9657 & \text { to } & 1.0306 & 0.888\end{array}$ $1 \mathrm{~h}$ maximum $24 \mathrm{~h}$ average D-3 $8 \mathrm{~h}$ average $\quad 0.9987 \quad 0.9670$ to $1.0314 \quad 0.939$ $24 \mathrm{~h}$ average

$\begin{array}{lllllll}0.9968 & 0.9671 & \text { to } & 1.0273 & 0.836 & 1.0380 & 0.9635\end{array}$

$1.0838 \quad 0.9788$ D-4

$\begin{array}{llllll}8 \mathrm{~h} \text { average } & 1.0067 & 0.9751 & \text { to } & 1.0393 & 0.681\end{array}$

$1 \mathrm{~h}$ maximum $24 \mathrm{~h}$ average PM10

D-2

D-3

D-4

$\mathrm{NO}_{2}$

$\mathrm{D}-1$

D-2

D-3

$\begin{array}{lllll}0.9978 & 0.9684 & \text { to } & 1.0280 & 0.887\end{array}$

1.0169

0.9321

$1.0248 \quad 0.9260$

to 1.1342

0.635

$1.0041 \quad 0.5586$

$1.0143 \quad 0.9518$

$0.9518 \quad 0.8106$

$1.0047 \quad 0.8532$

0.8520

\begin{tabular}{lll}
1.7995 & 0.989 \\
\hline & 1.1167 & 0.545
\end{tabular}

$0.9780 \quad 0.9202$

$\begin{array}{lllll}1.0307 & 0.9367 & \text { to } & 1.1336 & 0.533\end{array}$

$\begin{array}{lllll}0.9931 & 0.9029 & \text { to } & 1.0918 & 0.887 \\ 0.9462 & 0.8607 & \text { to } & 1.0396 & 0.250\end{array}$

$\begin{array}{lllll}0.8960 & 0.7689 & \text { to } & 1.0434 & 0.158\end{array}$

1.152

0.908

0.9427

0.7689

$\begin{array}{ll}1.1262 & 0.8767\end{array}$

$\begin{array}{ll}1.0434 & 0.158 \\ 1.4449 & 0.631\end{array}$

$\begin{array}{llll}0.8767 & \text { to } & 1.4449 & 0.349 \\ 0.7047 & \text { to } & 1.1306 & 0.348\end{array}$

$1.1306 \quad 0.348$

$\mathrm{SO}_{2}$

$\begin{array}{lllll}0.9462 & 0.8607 & \text { to } & 1.0396 & 0.250\end{array}$

$\begin{array}{lllll}0.653 & 0.164 & \text { to } & 2.5822 & 0.544\end{array}$

$\begin{array}{lllll}1.0069 & 0.5986 & \text { to } & 1.6893 & 0.979\end{array}$

$\begin{array}{lllll}0.8916 & 0.2525 & \text { to } & 3.1284 & 0.858\end{array}$

$\begin{array}{lllll}0.8763 & 0.5138 & \text { to } & 1.4905 & 0.626 \\ 1.2539 & 0.7405 & \text { to } & 2.1174 & 0.397\end{array}$

$0.7231 \quad 0.1983$

$1.4852 \quad 0.8956$

$2.4567 \quad 0.123$

1.3587

0.3735

$\mathrm{NO}_{2}$, nitrogen dioxide; PM10, particulate matter; $\mathrm{SO}_{2}$, sulfur dioxide; aOR, adjusted odds ratio. 
Figure 1 Dose relationship between ozone and ischaemic stroke events $((A)$, recurrent ischaemic stroke subgroup and (B), large artery ischaemic stroke subgroup).
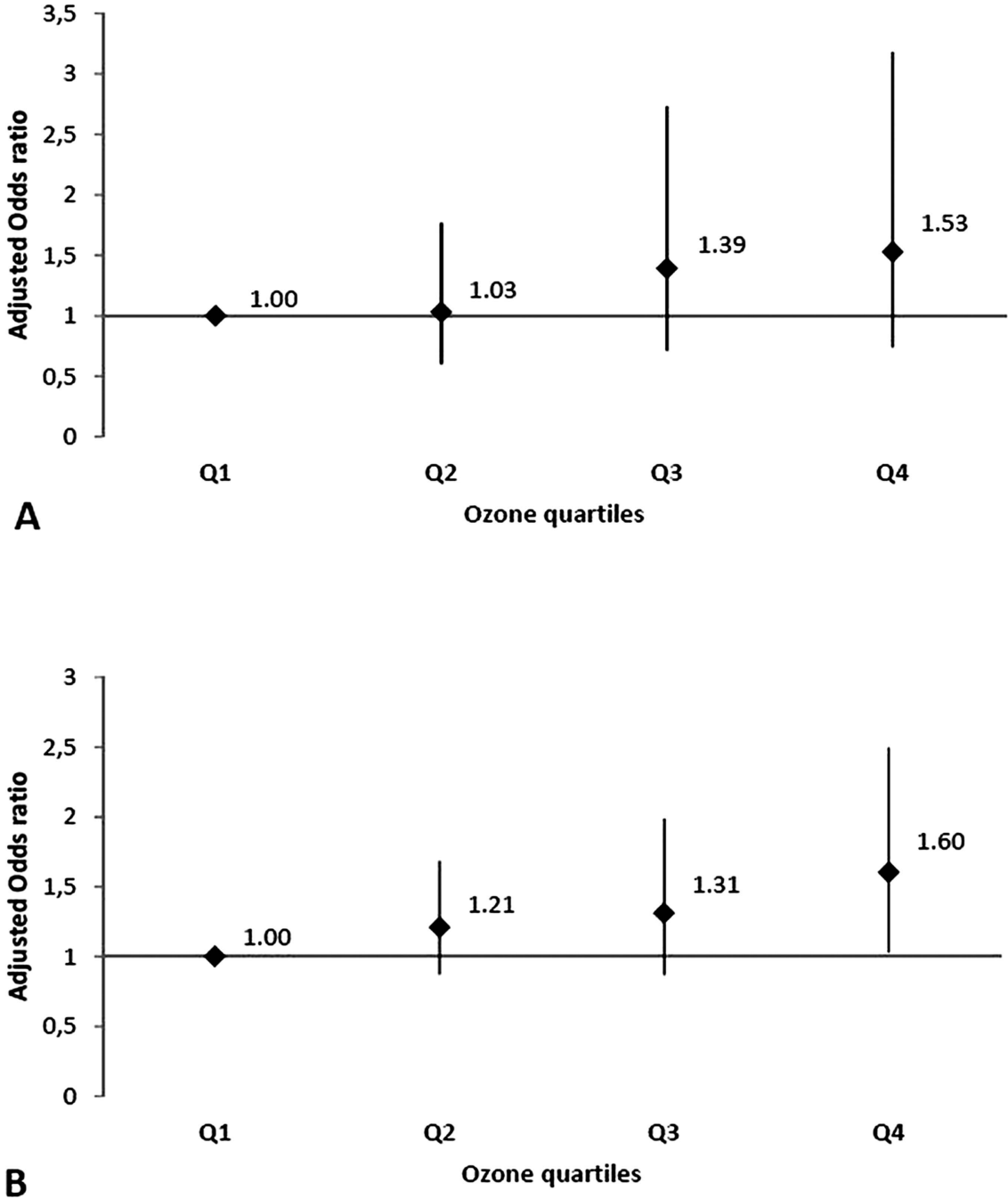

crossover design 815171921 or the time series analysis method. ${ }^{3121622}$ Consistent with our results, the majority of these studies do not observe the relationship between $\mathrm{O}_{3}$ exposure and occurrence of ischaemic stroke. 3817192122 Whenever a relationship was revealed, the association was borderline significant ${ }^{16}$ or was not confirmed by a second study on the same area of investigation. ${ }^{1519}$ Despite the fact that the link between ischaemic stroke and $\mathrm{O}_{3}$ exposure is not obvious, results in subgroup analyses seem to identify a population at risk for $\mathrm{O}_{3}$ exposure. In a recurrent ischaemic stroke subgroup, a significant increase of $12.1 \%$ (95\% CI $1.5 \%$ to $23.9 \%$ ) in stroke risk was observed for each increase of $10 \mu \mathrm{g} / \mathrm{m}^{3}$ of $\mathrm{O}_{3}$ concentration during previous days (mean D-1, D-2 and D-3 lag). Consistent with this result, a populationbased study in Dijon (France) revealed the same association (OR 1.150; $95 \%$ CI 1.027 to 1.209 ) with 3 days lag. ${ }^{19}$ Similarly, a significant association was observed in a large artery stroke subgroup (mean D-3, D-4, OR 1.080; $95 \%$ CI 1.002 to 1.166$)$. This link was observed in the previous study (Dijon) especially in this stroke aetiological subgroup. ${ }^{15}$ Associations in other ischaemic stroke subgroups are not systematically confirmed (age, gender, vascular risk factors and season). ${ }^{3} 15192122$ Our study confirms the short-term effects of $\mathrm{O}_{3}$ exposure on patients with stroke with high vascular risk. ${ }^{15} 19$

Our findings suggest that exposure to $\mathrm{O}_{3}$, the main photochemical pollutant, could increase the risk of ischaemic stroke in population subgroups (recurrent stroke, large arteries stroke) particularly exposed to vascular risk factors inducing atherosclerosis. Physiopathological pathways linking ischaemic stroke and $\mathrm{O}_{3}$ exposure still remain largely unclear and probably complex. Some studies support a delayed effect (1-3 days lag) between acute exposure of $\mathrm{O}_{3}$ pollution and stroke onset. $^{15}{ }^{19} \mathrm{O}_{3}$ urban pollution effects on healthy participants are associated with systemic inflammatory responses, oxidative stress and blood coagulation. ${ }^{25} 26$ These acute phenomena induced by even low levels of $\mathrm{O}_{3}$ could be the trigger of ischaemic event consecutively to atherosclerotic plaque instability, alterations in endothelial function, and increased coagulation and thrombosis. ${ }^{27}$ As suggested by Henrotin et $a l,{ }^{19}$ we hypothesised that short-term effect of $\mathrm{O}_{3}$ exposure could be involved especially among participants with high vascular risk.

In order to establish a causal relationship between $\mathrm{O}_{3}$ exposure and stroke onset, we studied the exposureresponse relationship, the main criteria identified by 
Figure 2 Baseline characteristics according to recurrent stroke subgroup $(A)$ and large artery stroke subgroup

(B) $\left({ }^{*} p<0.05\right)$.

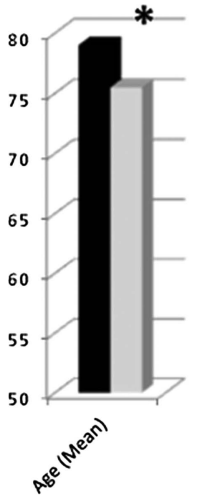

A

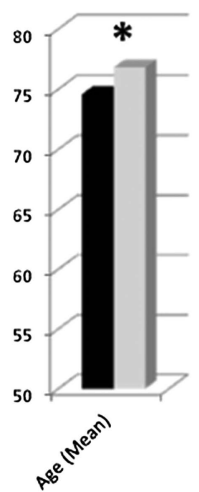

B

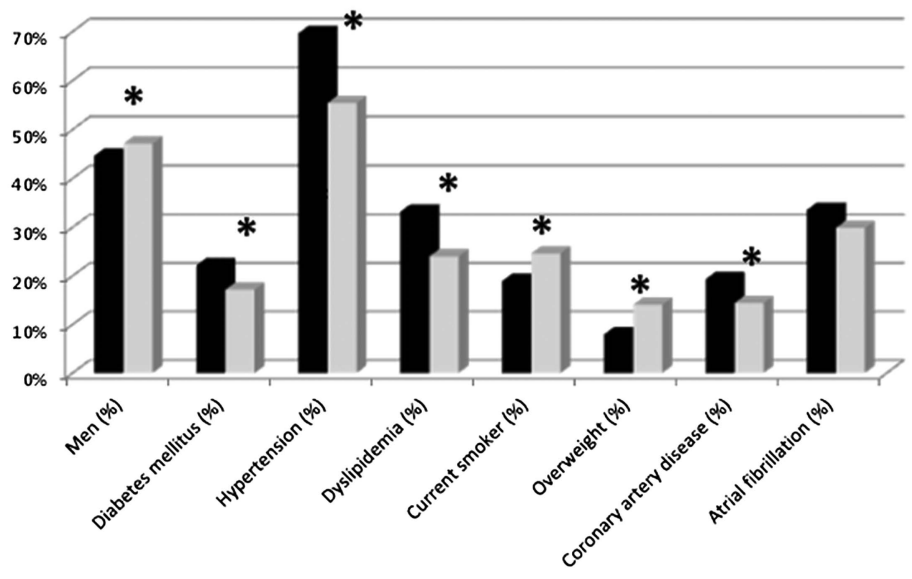

- Recurrent stroke $(\mathrm{n}=\mathbf{2 8 0}) \quad$ Incident stroke $(\mathrm{n}=1449)$

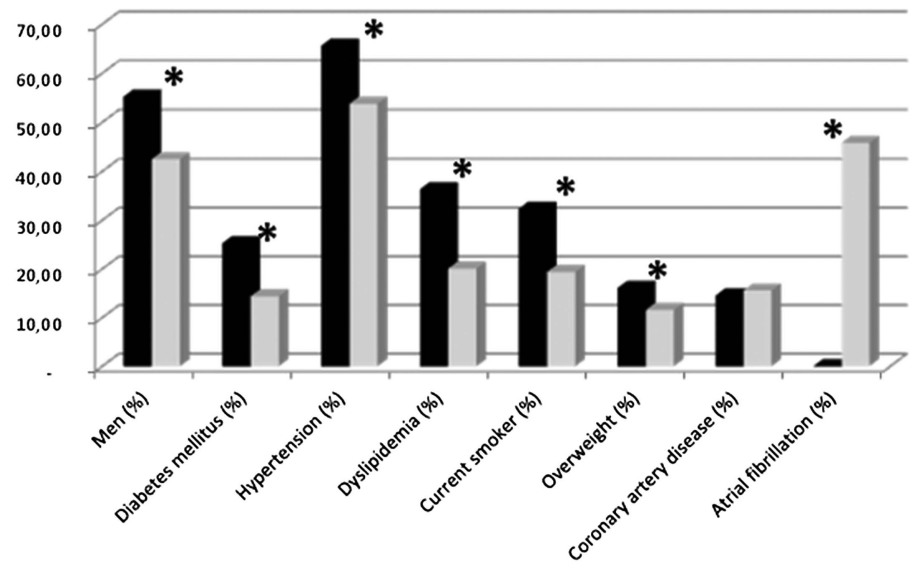

- Large artery stroke $(n=578) \quad$ Other stroke $(n=1151)$

using adjusted models for each of the other pollutants $\left(\mathrm{NO}_{2}, \mathrm{SO}_{2}\right.$ and PM10). PM2.5 was not studied because it was not monitored in Nice.

\section{SUMIMARY}

The consequences of $\mathrm{O}_{3}$ pollution on the respiratory system and mortality are well documented. ${ }^{1}$ Our results confirm the relationship between low-level $\mathrm{O}_{3}$ exposure and ischaemic stroke in high vascular risk subgroup with linear exposure-response relationship, independently of other pollutants and meteorological parameters. Reproducibility of previous results is one of the main Hill's criterion to induce causality of $\mathrm{O}_{3}$ exposure. Even if the individual's risk is low, to identify an association between $\mathrm{O}_{3}$ and ischaemic stroke incidence is important from a public health point of view, since a large population is concerned. The physiopathological processes underlying this association between ischaemic stroke and $\mathrm{O}_{3}$ exposure remain to be investigated.

Acknowledgements The authors would like to thank AirPACA association and Sentiweb network who provided, respectively, daily measures of outdoor air pollution and data on influenza epidemics in the region of Provence-AlpesCote-d'Azur. especially particles. Effects of $\mathrm{O}_{3}$ alone are not modified 
Contributors All authors have contributed to (1) substantial contributions to conception and design, acquisition of data or analysis and interpretation of data; (2) drafting the manuscript or revising it critically for important intellectual content and (3) final approval of the version to be published.

Funding This research received no specific grant from any funding agency in the public, commercial or not-for-profit sectors.

Competing interests None.

Provenance and peer review Not commissioned; externally peer reviewed.

Data sharing statement No additional data are available.

Open Access This is an Open Access article distributed in accordance with the Creative Commons Attribution Non Commercial (CC BY-NC 3.0) license, which permits others to distribute, remix, adapt, build upon this work noncommercially, and license their derivative works on different terms, provided the original work is properly cited and the use is non-commercial. See: http:// creativecommons.org/licenses/by-nc/3.0/

\section{REFERENCES}

1. Brunekreef B, Holgate ST. Air pollution and health. Lancet 2002;360:1233-42

2. Logan WP. Mortality in the London fog incident, 1952. Lancet 1953;1:336-8.

3. Ponka A, Virtanen M. Low-level air pollution and hospital admissions for cardiac and cerebrovascular diseases in Helsinki. Am J Public Health 1996;86:1273-80

4. Samet JM, Dominici F, Curriero FC, et al. Fine particulate air pollution and mortality in 20 U.S. cities, 1987-1994. N Engl J Med 2000;343:1742-9.

5. Zeller M, Giroud M, Royer C, et al. Air pollution and cardiovascular and cerebrovascular disease: epidemiologic data. Presse Med 2006;35:1517-22.

6. Larrieu S, Jusot JF, Blanchard M, et al. Short term effects of air pollution on hospitalizations for cardiovascular diseases in eight French cities: the PSAS program. Sci Total Environ 2007;387:105-12.

7. Hong YC, Lee JT, Kim H, et al. Air pollution: a new risk factor in ischemic stroke mortality. Stroke 2002;33:2165-9.

8. Tsai SS, Goggins WB, Chiu HF, et al. Evidence for an association between air pollution and daily stroke admissions in Kaohsiung, Taiwan. Stroke 2003;34:2612-16.

9. Wellenius GA, Schwartz J, Mittleman MA. Air pollution and hospital admissions for ischemic and hemorrhagic stroke among medicare beneficiaries. Stroke 2005;36:2549-53.

10. Maheswaran R, Haining RP, Brindley $\mathrm{P}$, et al. Outdoor air pollution and stroke in Sheffield, United Kingdom: a small-area leve geographical study. Stroke 2005;36:239-43.

11. Low RB, Bielory L, Qureshi Al, et al. The relation of stroke admissions to recent weather, airborne allergens, air pollution, seasons, upper respiratory infections, and asthma incidence, September 11, 2001, and day of the week. Stroke 2006;37:951-7.

12. Chan CC, Chuang KJ, Chien LC, et al. Urban air pollution and emergency admissions for cerebrovascular diseases in Taipei, Taiwan. Eur Heart J 2006;27:1238-44

13. Ballester $\mathrm{F}$, Rodriguez $\mathrm{P}$, Iniguez $\mathrm{C}$, et al. Air pollution and cardiovascular admissions association in Spain: results within the EMECAS project. J Epidemiol Community Health 2006;60:328-36.

14. Kettunen J, Lanki $T$, Tiittanen $P$, et al. Associations of fine and ultrafine particulate air pollution with stroke mortality in an area of low air pollution levels. Stroke 2007;38:918-22.

15. Henrotin JB, Besancenot JP, Bejot $Y$, et al. Short-term effects of ozone air pollution on ischaemic stroke occurrence: a case-crossover analysis from a 10-year population-based study in Dijon, France. Occup Environ Med 2007;64:439-45.

16. Lisabeth LD, Escobar JD, Dvonch JT, et al. Ambient air pollution and risk for ischemic stroke and transient ischemic attack. Ann Neurol 2008;64:53-9.

17. Oudin A, Stromberg U, Jakobsson K, et al. Estimation of short-term effects of air pollution on stroke hospital admissions in southern Sweden. Neuroepidemiology 2010;34:131-42.

18. Maheswaran R, Pearson T, Smeeton NC, et al. Impact of outdoor air pollution on survival after stroke: population-based cohort study. Stroke 2010;41:869-77

19. Henrotin JB, Zeller M, Lorgis L, et al. Evidence of the role of short-term exposure to ozone on ischaemic cerebral and cardiac events: the Dijon Vascular Project (DIVA). Heart 2010;96:1990-6.

20. Hennerici MG. Report of the 20th European Stroke Conference, Hamburg, May 24-27, 2011. Cerebrovasc Dis 2011;32:589-613.

21. Mechtouff L, Canoui-Poitrine F, Schott AM, et al. Lack of association between air pollutant exposure and short-term risk of ischaemic stroke in Lyon, France. Int J Stroke 2012;7:669-74.

22. Maheswaran R, Pearson T, Smeeton NC, et al. Outdoor air pollution and incidence of ischemic and hemorrhagic stroke: a small-area level ecological study. Stroke 2012;43:22-7.

23. Chen R, Zhang Y, Yang C, et al. Acute effect of ambient air pollution on stroke mortality in the China air pollution and health effects study. Stroke 2013;44:954-60.

24. $\mathrm{Xu} X$, Sun $\mathrm{Y}, \mathrm{Ha} \mathrm{S}$, et al. Association between ozone exposure and onset of stroke in Allegheny County, Pennsylvania, USA, 19942000. Neuroepidemiology 2013;41:2-6.

25. Chuang KJ, Chan CC, Su TC, et al. The effect of urban air pollution on inflammation, oxidative stress, coagulation, and autonomic dysfunction in young adults. Am J Respir Crit Care Med 2007;176:370-6.

26. Jang AS, Choi IS, Yang SY, et al. Antioxidant responsiveness in BALB/c mice exposed to ozone. Respiration 2005;72:79-84.

27. O'Neill MS, Veves A, Zanobetti A, et al. Diabetes enhances vulnerability to particulate air pollution-associated impairment in vascular reactivity and endothelial function. Circulation 2005;111:2913-20.

28. Dab W, Segala C, Dor F, et al. Air pollution and health: correlation or causality? The case of the relationship between exposure to particles and cardiopulmonary mortality. J Air Waste Manag Assoc 2001;51:220-35. 